\title{
COMMENTS FROM THE EDITOR
}

\section{INTRODUCTION OF CLINICAL-PATHOLOGIC CONFERENCES SECTION}

I this issue of the Journal we are initiating a series of Clinical-Pathologic Conferences in General Thoracic Surgery. They will also appear on the CTSNet, which is especially suitable for this type of communication. The series is in response to requests by the readership of the Journal for greater clinical relevance and more general thoracic surgery content. The conferences will appear three to four times a year and will come initially from the Barnes-Jewish Hospital of Washington University

J Thorac Cardiovasc Surg 1999;117:846

Copyright (C) 1999 by Mosby, Inc.

$0022-5223 / 99 \$ 8.00+0 \quad \mathbf{1 2 / 1 / 9 7 6 1 5}$ in St Louis. The series will focus on the use of diagnostic and therapeutic judgment and, at times, emphasize newer modalities. We hope you will enjoy this new addition, and we will welcome your comments.

In addition, the Editor would like to remind the readership of our two sister publications, edited by Dr James Cox and sponsored by The American Association for Thoracic Surgery. The Seminars in Thoracic and Cardiovascular Surgery contains outstanding reviews by well-know authorities emphasizing clinical aspects of cardiothoracic surgery. The Operative Techniques in Thoracic and Cardiovascular Surgery superbly illustrates various surgical techniques by master clinicians.

John A. Waldhausen, MD 